\title{
Understanding the ORR Electrocatalysis on Co-Mn Oxides
}

Wang Wang, ${ }^{\dagger}{ }^{\dagger}$ Ershuai Liu, ${ }^{\dagger}$ Youcheng Hu, ${ }^{\star}$ Li Jiao, ${ }^{\dagger}$ Praveen Kolla, ${ }^{\dagger}$ Yucheng Liu, ${ }^{\star}$ Meihua Tang,

${ }^{\ddagger}$ Jin Luo, ${ }^{*}$ Qiang Sun, ${ }^{\dagger}$ Shengli Chen,${ }^{*} * *$ Qingying Jia, ${ }^{\dagger}, *$ Sanjeev Mukerjee ${ }^{\dagger} * *$

${ }^{\dagger}$ Department of Chemistry and Chemical Biology, Northeastern University Center for Renewable Energy Technology, 317 Egan Research Center, 360 Huntington Avenue, Boston, Massachusetts 02115, United States.

$\$$ Hubei Electrochemical Power Sources Key Laboratory, Department of Chemistry, Wuhan University, Wuhan 430072, China. 

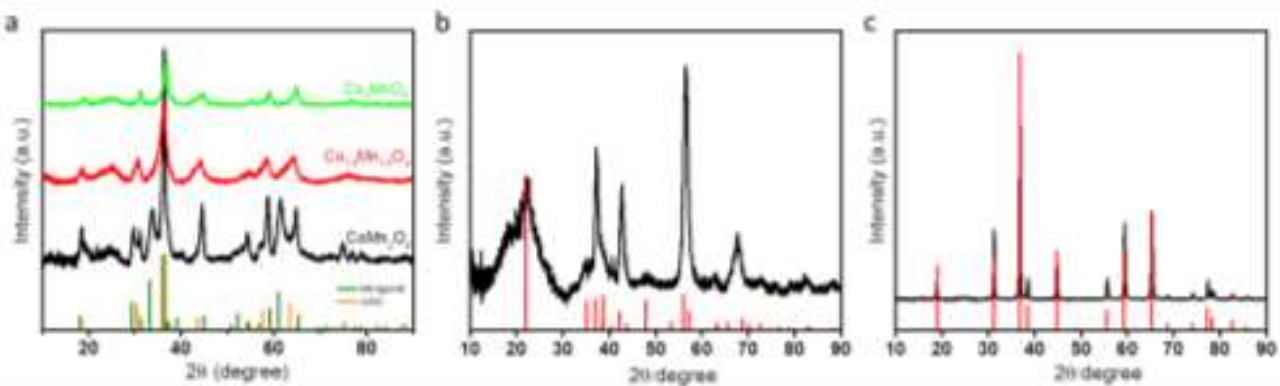

Figure S1. The XRD patterns of the Co-Mn spinel oxides (a) with different atomic ratio of Co and $\mathrm{Mn}\left(2: 1,1: 1\right.$ and 1:2). The XRD patterns of $\mathrm{MnO}_{2}(\mathrm{~b})$ and $\mathrm{Co}_{3} \mathrm{O}_{4}(\mathrm{c})$.
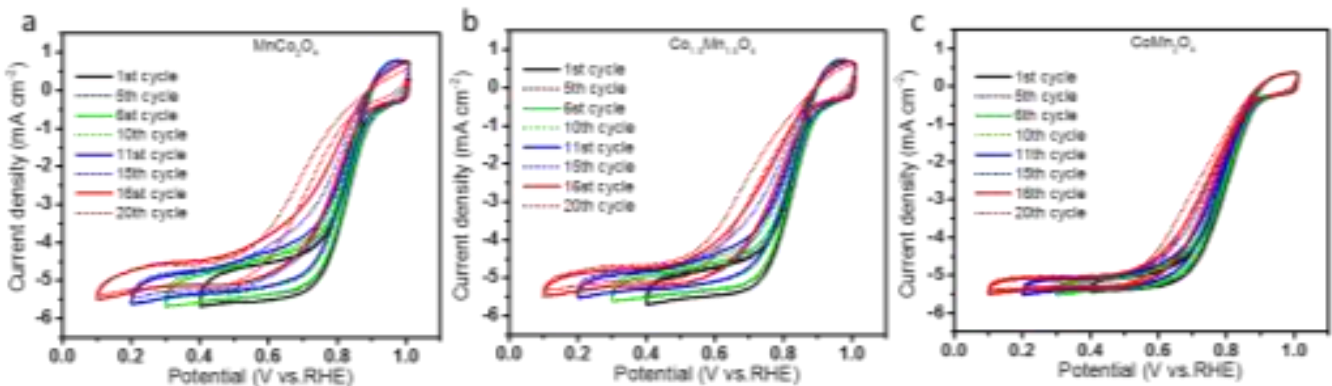

Figure S2. The polarization curves of the Co-Mn spinel oxides with different atomic ratio of Co and Mn (2:1, 1:1 and 1:2) as a function of the CV cycles, the profiles were collected from the same electrode under different potential windows.

a

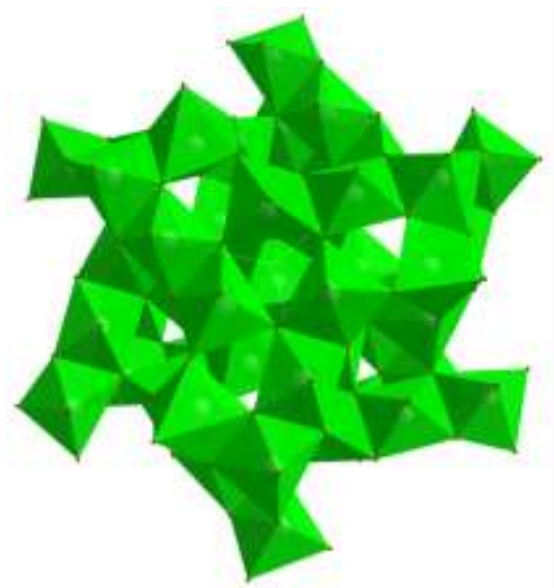

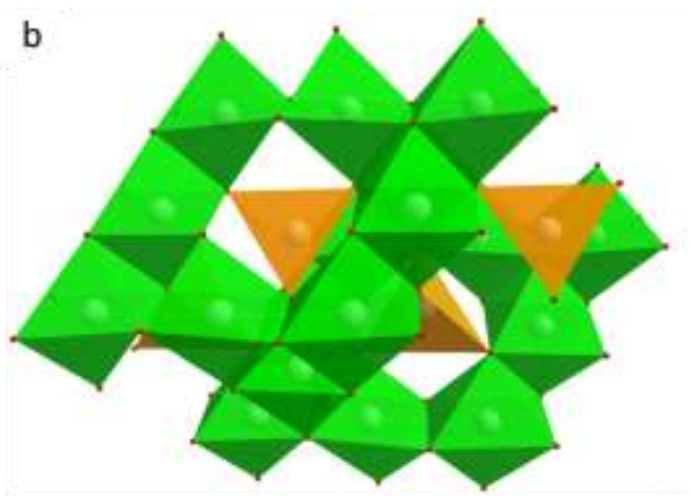

Figure S3. The crystal structure of $\mathrm{Mn}_{2} \mathrm{O}_{3}$ (a) and $\mathrm{Mn}_{3} \mathrm{O}_{4}$ (b). The green and orange polyhedrals represent $\mathrm{Mn}-\mathrm{O}_{6}$ octahedral and $\mathrm{Mn}-\mathrm{O}_{4}$ tetrahedral, respectively. 


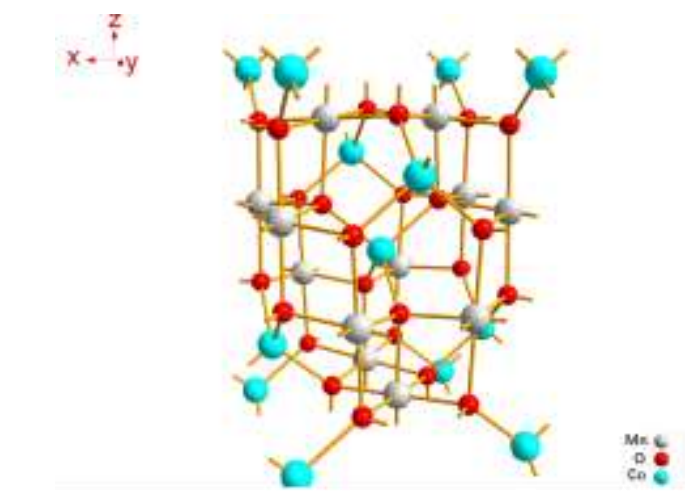

Figure S4. The primitive cell structure of $\mathrm{CoMn}_{2} \mathrm{O}_{4}$.

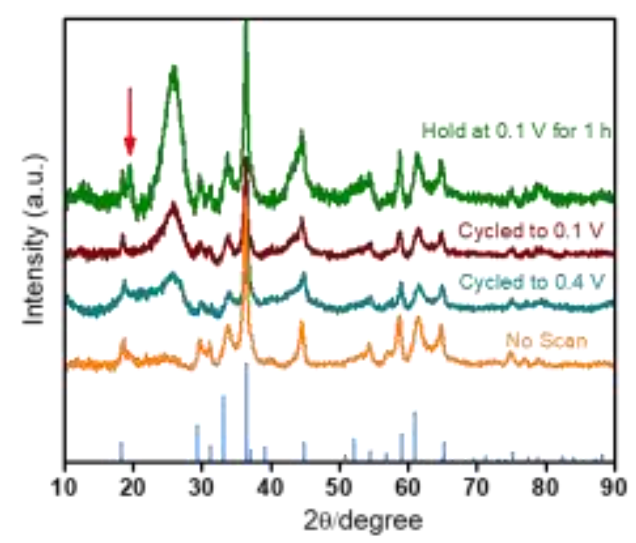

Figure S5. The XRD patterns of the catalyst without electrochemical scan, cycled at $1.0 \mathrm{~V}$ $0.4 \mathrm{~V}$ for 5 cycles, cycled at $1.0 \mathrm{~V}-0.1 \mathrm{~V}$ for 5 cycles and held at $0.1 \mathrm{~V}$ for $1 \mathrm{~h}$.

Table S1. The summarization of the peak information from the CV

\begin{tabular}{|c|c|c|c|c|}
\hline & $1.0 \mathrm{~V}-0.4 \mathrm{~V}$ & $1.0 \mathrm{~V}-0.3 \mathrm{~V}$ & $1.0 \mathrm{~V}-0.2 \mathrm{~V}$ & $1.0 \mathrm{~V}-0.1 \mathrm{~V}$ \\
\hline Anodic peak position (V) & 0.994 & 1.007 & 1.053 & 1.095 \\
\hline $\begin{array}{c}\text { Cathodic peak position } \\
\text { (V) }\end{array}$ & 0.791 & 0.756 & 0.685 & 0.646 \\
\hline $\begin{array}{c}\text { Potential difference of the } \\
\operatorname{redox}(\mathrm{V})\end{array}$ & 0.203 & 0.251 & 0.368 & 0.449 \\
\hline $\begin{array}{l}\text { Anodic peak area } \\
\qquad\left(\mathrm{mC} / \mathrm{cm}^{2}\right)\end{array}$ & 4.198 & 7.061 & 9.835 & 12.50 \\
\hline $\begin{array}{l}\text { Cathodic peak area } \\
\qquad\left(\mathrm{mC} / \mathrm{cm}^{2}\right)\end{array}$ & 5.078 & 8.660 & 10.921 & 12.740 \\
\hline
\end{tabular}

